\title{
An audit of the knowledge and attitudes of doctors towards Surgical Informed Consent (SIC)
}

\author{
Bushra Ashraf ${ }^{1}$, Nasira Tasnim ${ }^{1}$, Muhammad Saaiq $q^{2, *}$, Khaleeq-Uz-Zaman $^{3}$
}

\begin{abstract}
Background: The Surgical Informed Consent (SIC) is a comprehensive process that establishes an informationbased agreement between the patient and his doctor to undertake a clearly outlined medical or surgical intervention. It is neither a casual formality nor a casually signed piece of paper. The present study was designed to audit the current knowledge and attitudes of doctors towards SIC at a tertiary care teaching hospital in Pakistan.

Methods: This cross-sectional qualitative investigation was conducted under the auspices of the Department of Medical Education (DME), Pakistan Institute of Medical Sciences (PIMS), Shaheed Zulfiqar Ali Bhutto Medical University (SZABMU), Islamabad over three months period. A 19-item questionnaire was employed for data collection. The participants were selected at random from the list of the surgeons maintained in the hospital and approached face-to-face with the help of a team of junior doctors detailed for questionnaire distribution among them. The target was to cover over $50 \%$ of these doctors by convenience sampling.

Results: Out of 231 respondents, there were 32 seniors while 199 junior doctors, constituting a ratio of 1:6.22. The respondents variably responded to the questions regarding various attributes of the process of SIC. Overall, the junior doctors performed poorer compared to the seniors.

Conclusion: The knowledge and attitudes of our doctors particularly the junior ones, towards the SIC are less than ideal. This results in their failure to avail this golden opportunity of doctor-patient communication to guide their patients through a solidly informative and legally valid SIC. They are often unaware of the essential preconditions of the SIC; provide incomplete information to their patients; and quite often do not ensure direct involvement of their patients in the process. Additionally they lack an understanding of using interactive computer-based programs as well as the concept of nocebo effect of informed consent.

Keywords: Surgical Informed Consent (SIC), Consent, Nocebo Effect of Informed Consent, Surgery

Copyright: ๑ 2014 by Kerman University of Medical Sciences

Citation: Ashraf B, Tasnim N, Saaiq M, Zaman KU. An audit of the knowledge and attitudes of doctors towards Surgical Informed Consent (SIC). Int J Health Policy Manag 2014; 3: 315-321. doi: 10.15171/ijhpm.2014.109
\end{abstract}

Article History:

Received: 22 July 2014

Accepted: 26 October 2014

ePublished: 27 October 2014

\section{*Correspondence to:}

Muhammad Saaiq

Email: muhammadsaaiq5@gmail.com

\section{Key Messages}

Implications for policy makers

- Given the considerable deficiencies in the knowledge and attitudes of doctors regarding Surgical Informed Consent (SIC), there is a need for creating awareness among them about the negative impact of these deficiencies on the overall well-being of their patients.

- A structured SIC template should be developed for the institution and be enforced on the operating surgeons to document the process of SIC before embarking on any surgeries.

- There is a need for formal training sessions and workshops for surgical residents and house officers to improve their knowledge and skills regarding SIC. The specialists and faculty should also have similar capacity building sessions as part of their Continued Professional Development (CPD).

- There is a need to introduce more advanced technologies such as computer-based interactive programs to enhance the quality of the SIC process.

Implications for public

Awareness of the patients regarding adequacy of Surgical Informed Consent (SIC) is imperative to improve the SIC process, which, in turn, will enhance the patient satisfaction and reduce their misunderstandings with surgical staff.

\section{Introduction}

The Surgical Informed Consent (SIC) is a comprehensive process that involves a competent patient, a clearly communicating doctor, and transfer of focused information about the planned surgical procedure. The basic components of SIC thus include preconditions, information, and voluntary willingness. The preconditions for a valid SIC include the patient's competence and voluntariness for the procedure in question. The information provided must be adequate and comprehensible (1-3).

The information provided should particularly include medical facts about the patient's condition, details of the 
proposed procedures, the potential risks and benefits of the procedure and the alternatives to the proposed procedure including the natural course of non-treatment. All this information must be disclosed by the operating surgeon himself to the patient to help him arrive at informed decision-making about his treatment. A well-defined care plan incorporating the surgeon's advice should be discussed and it must be ensured that the patient understands all this information (3-6).

The objective of the present study was to audit the current knowledge and attitudes of surgical doctors towards the SIC at a tertiary care teaching hospital in a Pakistan.

\section{Methods}

This cross-sectional study was carried out by the Department of Medical Education (DME), Pakistan Institute of Medical Sciences (PIMS), Shaheed Zulfiqar Ali Bhutto Medical University (SZABMU), Islamabad over three months period (from January 01, 2014 to March 31, 2014).

PIMS is the tertiary care teaching dispensation affiliated with the SZABMU and is one of the country's leading medical institutions, attracting doctors from all parts of the country (Pakistan) as well as abroad, to pursue various postgraduate residency programs.

\section{Study participants}

The study population included the junior surgical doctors (i.e. house-officers and postgraduate residents) and senior surgeons (i.e. surgical specialists and surgical faculty members) working in various surgical disciplines of PIMS. The surgical specialties included general surgery, orthopedics surgery, plastic surgery, burns surgery, neurosurgery, obstetrics and gynecology, eye surgery, maxillofacial surgery, otorhinolaryngology, hepatobiliary surgery, urology, and cardiovascular surgery. The participants were selected at random from the list of the surgeons in the hospital and approached face-to-face, with the help of a team of junior doctors detailed for questionnaire distribution among them. The target was to cover over $50 \%$ of these doctors by convenience sampling. The questionnaire was completed anonymously.

\section{Study questionnaire}

A self-administered questionnaire was employed for the study. The aim was to cover all fundamental aspects of the knowledge and relevant attitudes that surround the process of SIC and hence generate a representative data that could serve as a valid outcome variable. The questionnaire was prepared by consulting previously used and validated questionnaires employed by other researchers $(3,5-8)$.

We employed a series of questions to cover the fundamental aspects of knowledge and relevant attitudes of doctors that impact the consent process. Pretesting of the questionnaire was performed on a limited number $(n=15)$ of surgeons and subsequent language modifications and amendments were done in light of their suggestions. The final refined version of the questionnaire contained the following nineteen items (summarized in Tables 1 and 2).
The questionnaire entailed the age cut off of 14 years as it is the officially accepted cut off point to distinguish children from adults in our hospital as well as elsewhere in other hospitals in our country. The law does not strictly define the age cut off as for as the SIC is concerned, hence is left to the discretion of individual healthcare institutions.

\section{Statistical analysis}

The data were analyzed through SPSS 17 (SPSS Inc., Chicago, IL, USA). The nominal variables were reported as frequency and percentages. The numerical data were reported as Mean \pm SD. The responses to the questions were recorded and descriptive statistics (i.e. frequency and percentages) were employed to calculate the various qualitative variables under study.

\section{Results}

Response rate

In the target population of 300 surgical doctors contacted, 231 doctors returned the questionnaires duly answered in all respects, constituting a response rate of $77 \%$. The nonrespondents were excluded from further analyses.

\section{Demographic features of the included doctors}

Overall there were 134 males (58\%) and 97 female respondents (42\%). Among them, there were 32 seniors while 199 junior doctors, constituting a ratio of 1:6.22 respectively. The junior doctors ranged in age from 22-35 years with a mean age of $26.60 \pm 3.77$ years whereas the senior doctors were aged 36-59 years with mean age of $44.96 \pm 9.68$ years. There were 113 males among the junior doctors while the remainder 86 were females. Among the senior doctors there were 21 males and 11 females.

The breakdown of the respondents with respect to their surgical disciplines includes obstetrics and gynecology $(\mathrm{n}=$ $46)$, general surgery $(n=39)$, orthopedics surgery $(n=33)$, urology $(n=26)$, otorhinolaryngology $(n=23)$, neurosurgery $(n=18)$, maxillofacial surgery $(n=15)$, plastic surgery $(n=$ $9)$, eye surgery $(n=9)$, hepatobiliary surgery $(n=8)$, and cardiovascular surgery $(n=4)$ and burns surgery $(n=1)$. There were no significant differences between responses to the questions with respect to the surgical disciplines of the respondents.

Responses to the questions regarding knowledge and current hospital practices of the process of SIC are shown in Tables 1 and 2 respectively.

The participants variably responded to the questions regarding various attributes of the process of SIC. Overall, the junior doctors performed poorer compared to the seniors. Instead of the SIC being obtained by the operating surgeon himself, majority of the respondents delegated its responsibility to the staff nurse or junior doctors. Instead of directly involving the patient and obtaining the SIC from patient himself/herself, more responses were observed in favor of obtaining it from the attendants or husbands. The night before surgery was stated as the most frequently employed time for obtaining the SIC. There was neither any formal standard used to ensure the competence of the person from whom the SIC was 
Table 1. Responses to the questions regarding knowledge of the key aspects of the SIC $(n=231)$

\begin{tabular}{|c|c|c|}
\hline & Junior doctors $(n=199)$ & Senior doctors $(n=32)$ \\
\hline \multicolumn{3}{|c|}{ For which type of surgical procedure the SIC should be sought? } \\
\hline All procedures & $39(19.59 \%)$ & $27(84.37 \%)$ \\
\hline Elective ones & $43(21.60 \%)$ & - \\
\hline Emergency cases only & $117(58.79 \%)$ & $2(6.25 \%)$ \\
\hline Critical cases only & - & $3(9.37 \%)$ \\
\hline Others & - & - \\
\hline \multicolumn{3}{|c|}{ Patient of what age do you think is able to give a valid SIC? } \\
\hline All ages & $127(63.81 \%)$ & - \\
\hline Patients aged above 14 & $56(28.14 \%)$ & $26(81.25 \%)$ \\
\hline Depending on the individual's intelligence & $3(1.50 \%)$ & $5(15.62 \%)$ \\
\hline Depending on clinical judgment of maturity & $6(3.01 \%)$ & $1(3.12 \%)$ \\
\hline Others & $7(3.51 \%)$ & - \\
\hline \multicolumn{3}{|l|}{ Do you inform your patient on the following? } \\
\hline The diagnosis and indication of operation & $163(81.90 \%)$ & $32(100 \%)$ \\
\hline The surgical procedure & $93(46.73 \%)$ & $32(100 \%)$ \\
\hline Likely complications & $3(1.50 \%)$ & $13(40.62 \%)$ \\
\hline Alternative treatment options & $1(0.50 \%)$ & $4(12.50 \%)$ \\
\hline Others & - & - \\
\hline \multicolumn{3}{|c|}{ Are the following items required in the SIC (elements of consent) } \\
\hline Evaluation of competence & - & $2(6.25 \%)$ \\
\hline Patient education & - & $1(0.50 \%)$ \\
\hline Recording of consent & $113(56.78 \%)$ & $25(78.12 \%)$ \\
\hline Patients' signature & $139(69.84 \%)$ & $21(65.62 \%)$ \\
\hline Surgeons' signature & $4(2.01 \%)$ & - \\
\hline Others & - & - \\
\hline \multicolumn{3}{|l|}{ Are you aware of the NEIC? } \\
\hline Yes & - & - \\
\hline No & $199(100 \%)$ & $32(100 \%)$ \\
\hline Others & - & - \\
\hline \multicolumn{3}{|c|}{ Do you think the process of SIC has any impact on the well-being of you patients? } \\
\hline Yes & - & - \\
\hline No & $199(100 \%)$ & $32(100 \%)$ \\
\hline Others & - & - \\
\hline \multicolumn{3}{|c|}{ Did you ever receive any formal training on the process of SIC? } \\
\hline Yes & - & - \\
\hline No & $199(100 \%)$ & $32(100 \%)$ \\
\hline Others & - & - \\
\hline
\end{tabular}

SIC= Surgical Informed Consent; NEIC= Nocebo Effect of Informed Consent

obtained, nor was any regular use of structured proforma. There was serious deficiency regarding communication of the likely complications as well as the available alternative treatment options. Also it was often not ensured if the patient understood the information. Although all the respondents endorsed that the process of SIC had impact on the well-being of their patients, none of them had ever received any formal training on the process of SIC (Tables 1 and 2).

\section{Discussion}

The present study is the first of its kind at our institute and it looked at the process of SIC in a doctors' perspective. Our study identified considerable deficiencies in the current knowledge and attitudes of our doctors toward this very crucial area of doctor-patient communication. Surprisingly certain studies from institutions in the western countries such as the USA, Europe, Netherlands and New Zealand have also reported a lack of doctors' knowledge regarding the process of SIC (1,3,7-10). Less than ideal level of working knowledge and attitudes regarding SIC on part of our doctors indicates a case for their focused education regarding SIC. Enhancing their education in this regard will certainly address the deficiencies identified by our study $(11,12)$.

In our study, the overall knowledge and attitudes the doctors did not conform to the established norms of SIC, with the junior doctors performing even poorer than specialists and the faculty. The junior doctors particularly the residents are usually the front line healthcare providers in developing as 
Table 2. Responses to the questions regarding current practices and attitudes towards SIC $(n=231)$

\begin{tabular}{|c|c|c|}
\hline & Junior doctors $(n=199)$ & Senior doctors $(n=32)$ \\
\hline \multicolumn{3}{|l|}{ Who obtains the SIC? } \\
\hline The operating surgeon himself & $3(1.50 \%)$ & $2(6.25 \%)$ \\
\hline The junior doctor on duty & $53(26.63 \%)$ & $14(43.75 \%)$ \\
\hline Staff nurse on duty & $143(71.85 \%)$ & $16(50 \%)$ \\
\hline Others & - & - \\
\hline \multicolumn{3}{|l|}{ From whom do you obtain the SIC? } \\
\hline The patient & $8(4.02 \%)$ & $7(21.87 \%)$ \\
\hline The attendants & $151(75.87 \%)$ & $25(78.12 \%)$ \\
\hline The husband & $23(11.55 \%)$ & - \\
\hline The father & $17(8.54 \%)$ & - \\
\hline Any other person & - & - \\
\hline Others & - & \\
\hline \multicolumn{3}{|l|}{ Which time do you obtain the SIC? } \\
\hline On the admission counter & $1(0.50 \%)$ & $2(6.25 \%)$ \\
\hline In the ward & $5(2.51 \%)$ & $9(28.12 \%)$ \\
\hline In the operating theatre & $20(10.05 \%)$ & - \\
\hline The night before surgery & $173(86.93 \%)$ & $21(65.62 \%)$ \\
\hline Others & - & - \\
\hline \multicolumn{3}{|c|}{ How do you check the if the patient is competent to obtain SIC? } \\
\hline Use own clinical judgment & $10(28.14 \%)$ & $6(18.75 \%)$ \\
\hline Use structured questionnaire & - & - \\
\hline Not using any standard & $183(91.95 \%)$ & $26(81.25 \%)$ \\
\hline Others & - & - \\
\hline \multicolumn{3}{|c|}{ What do you do if the next of kin is not available to obtain SIC? } \\
\hline Do not proceed to surgery & - & - \\
\hline Give consent on behalf of the patient & $181(90.95 \%)$ & $28(87.50 \%)$ \\
\hline Inform the hospital administration & $18(9.04 \%)$ & $4(12.50 \%)$ \\
\hline Others & - & - \\
\hline \multicolumn{3}{|c|}{ Do you use any structured proforma for obtaining SIC? } \\
\hline Yes & - & - \\
\hline No & $199(100 \%)$ & $32(100 \%)$ \\
\hline Others & - & - \\
\hline \multicolumn{3}{|c|}{ How do you ensure that the patient understood the information? } \\
\hline Repeat back & - & $1(3.12 \%)$ \\
\hline Do not ensure & $183(91.95 \%)$ & $31(96.87 \%)$ \\
\hline Others & - & - \\
\hline \multicolumn{3}{|c|}{ Do you have an institutional standard on complication rates? } \\
\hline Yes & - & - \\
\hline No & $199(100 \%)$ & $32(100 \%)$ \\
\hline Others & - & - \\
\hline \multicolumn{3}{|c|}{ Which complication percentage do you use to inform your patient in the process of SIC? } \\
\hline Rates from published literature & - & $25(78.12 \%)$ \\
\hline Rates from own department & - & - \\
\hline Personal rates & - & - \\
\hline None of these & 181 (90.95\%) & - \\
\hline Others & - & - \\
\hline \multicolumn{3}{|c|}{ Do you use any check prior to starting the surgical procedure if the SIC is correctly completed? } \\
\hline Yes & - & - \\
\hline No & $173(86.93 \%)$ & $29(90.62 \%)$ \\
\hline Others & - & - \\
\hline \multicolumn{3}{|c|}{ Which of the following supporting tools do you use for patient's education and guidance? } \\
\hline Leaflets & - & - \\
\hline Websites/software & - & - \\
\hline Movies & - & - \\
\hline Information personnel & - & - \\
\hline None of these & $193(96.98 \%)$ & $32(100 \%)$ \\
\hline Others & - & - \\
\hline \multicolumn{3}{|c|}{ Are you interested in using software for SIC? } \\
\hline \multicolumn{3}{|l|}{ Yes } \\
\hline No & 173 (86.93\%) & $27(84.37 \%)$ \\
\hline Others & & \\
\hline
\end{tabular}

SIC= Surgical Informed Consent 
well as developed countries, however they are often not well versed with the process of SIC, and hence err by not giving information about the potential complications of the planned procedures or alternative treatments and mostly provide only information on the benefits of particular surgical interventions (13-15). Lack of practical experience as well as deficient training on part of the residents in the critical area of doctor-patient communication are the possible explanations for their poor performance in the process of SIC $(7,9,16-20)$. Our findings of the study constitute a compelling evidence for educating residents in this particular area of doctor-patient communication in future.

In our study majority (84.37\%) of the senior doctors admitted that SIC was necessary for all surgical procedures, however only $19.59 \%$ among the juniors felt it essential for all procedures.

In response to the question as to how do you satisfy the needs of SIC when no next of kin is available in emergency situations, majority answered that they obtained the consent on their own. Certainly the hospital administration has a role to play in such situations, and we need to devise a mechanism so that doctors do not face frustration for tasks beyond their scope and capacity as surgeons.

In our study majority of the doctors said that the SIC should be sought and documented on the night prior to the planned surgery. Majority of doctors expressed that staff nurse has to obtain the consent. It cannot be over-emphasized that a valid SIC should only be obtained by the operating surgeon who is going to operate upon the patient. Also it is equally important to understand that the SIC is a continuous process that starts as soon as the doctor meets the patient and should continue after the operation to facilitate the patient's understanding of the procedure, benefits, anticipated risks of the operation and the post operative follow up period.

In our study majority of the doctors endorsed that the SIC should be obtained from either the attendants or husbands. This unethical trend of not directly involving the patients in the process of informed decision-making should be discouraged. Also the local custom of employing husbands as surrogates but not the vice versa in the process of SIC needs rectification by encouraging women empowerment.

In our study none of the doctors neither used computers in the process of SIC nor showed any inclination/interest in using the relevant software for this purpose in future. Indeed computers and other similar supporting tools have the potential to make the process easier for the doctors and better comprehensible for the patients. Such tools can further strengthen the doctor-patient trust. An integrated interactive computer program may be developed for case specific SIC. This will enhance recapitulation of the facts on part of the patients as well as save precious time of the surgeons. The additional gains with the use of computer programs for SIC would include better structure, improved quality, diminished consultation time and stimulated patient commitment. The time and effort saved for busy surgeons can better used for answering specific queries and concerns of the patient in brief consultation sessions with the patients $(1,21,22)$.

In our study majority of doctors admitted that they did not employ any structured proforma for the SIC. Since it is a crucial part of patient care, it needs to be standardized to conform to the accepted norms of the process. It will surely improve its quality, completeness, patient satisfaction, safety, and legal solidity (1,23-25). Structured SIC form has been successfully implemented in the daily practice of doctors in other countries (15).

As is evident from our study, our doctors under-estimate the information needs of their patients. Several published studies have also identified the fact that surgeons often underestimate the information needs of their surgical patients (26-28). Given the findings of our study, it will be logical to undertake further studies to explore why the younger generation of doctors are doing a worse job compared with their seniors. Is this a case of a lack of ethical training at undergraduate medical school or overt paternalism or simply a lack of practical experience? These issues whether educational or cultural will need to be addressed accordingly.

In our study none of the doctors knew the concept of Nocebo Effect of Informed Consent (NEIC). Nocebo phenomenon is the negative analogue of placebo phenomenon. In fact the SIC is an ethical responsibility of the doctors, however they should be prudent enough to strike a balance between what information is necessary and what information is going to further harm their already jeopardized patients. So while discussing negative outcomes with the patients they should wisely tailor their communication accordingly to avoid the undesirable NEIC (29-31).

We wanted to have more robust comparison of the findings of our study with similar published literature from particularly the other developing countries in our neighborhoods, however we could not find any quality publications from these countries. In glaring contrast to this situation, the majority of studies published from the developed countries are more focused on patients' perspectives of the process of SIC, with a recent growing trend towards the use of multimedia in the process and their impact on the patient's understanding of the content of SIC (32-39).

\section{Strengths, limitations and future directions}

Our study has some strengths as well as presents some limitations. It is the first institutional study which has attempted to objectively evaluate the process of SIC in the doctors' perspective and hence establish a baseline evidence-base of their knowledge and attitudes towards this crucial component of doctor-patient communication. The suboptimal level of knowledge and attitudes of particularly the junior doctors identified by the present study should motivate their formal training and capacity-building at both undergraduate level as well as during their postgraduate residency including internship period. Additionally a number of measures on both institutional and national level are needed to address the attitudinal and cultural barriers which serve as potential hinders to the successful implementation of the desired changes.

The limitations of the study include: Firstly, the study was a qualitative one rather than being a detailed quantitative analysis of the various complex factors that impact the 
knowledge and attitudes of doctors towards SIC in the context of the developing economy of Pakistan with its recognized limitations of the healthcare system. Secondly, response bias by the participants could not be completely eliminated as the questionnaire employed remained somewhat instructive on its own because of the close ended questions. Thirdly, the study was based on a single institution's data, and its findings cannot be generalized to the rest of the hospitals in Pakistan. We suggest future studies to confirm our findings and improve upon our limitations.

\section{Conclusion}

The knowledge and attitudes of our doctors particularly the junior ones, towards the SIC are less than ideal. This results in their failure to avail this golden opportunity of doctorpatient communication to guide their patients through a solidly informative and legally valid SIC. They are often unaware of the essential preconditions of the SIC; provide incomplete information to their patients; and quite often do not ensure direct involvement of their patients in the process. Additionally they lack an understanding of using interactive computer-based programs as well as the concept of nocebo effect of informed consent.

\section{Acknowledgements}

We are grateful to the following doctors for helping us in collecting data from the participants: Dr. Saad Siddiqui, Dr. Shahzad Ahmad, and Dr. Muhammad Salman Zaib.

\section{Ethical issues}

Informed consent was taken from the participants for inclusion in the study. The study was conducted in accordance with the Declaration of Helsinki of 1975, as revised in 1983 and anonymity of the participants was ensured.

\section{Competing interests}

The authors declare that they have no competing interests.

\section{Authors' contributions}

KUZ and NT conceived and designed the study. MS and BA performed the literature search and wrote the first draft of the manuscript. All authors participated in the data acquisition, analysis, and interpretation. All authors critically reviewed, refined, and approved the final version of the manuscript.

\section{Authors' affiliations}

${ }^{1}$ Department of Obstetrics and Gynecology, Mother and Child Health Centre, Pakistan Institute of Medical Sciences, Shaheed Zulfiqar Ali Bhutto Medical University, Islamabad, Pakistan. ${ }^{2}$ Department of Plastic Surgery and Burns, Pakistan Institute of Medical Sciences, Shaheed Zulfiqar Ali Bhutto Medical University, Islamabad, Pakistan. ${ }^{3}$ Departments of Neurosurgery and Medical Education, Pakistan Institute of Medical Sciences, Shaheed Zulfiqar Ali Bhutto Medical University, Islamabad, Pakistan.

\section{References}

1. Leclercq WK, Keulers BJ, Scheltinga MR, Spauwen PH, van der Wilt GJ. A review of surgical informed consent: past, present, and future. A quest to help patients make better decisions. World $\mathrm{J}$ Surg 2010; 34: 1406-15. doi: 10.1007/s00268-010-0542-0

2. Saaiq M, Zaman KU. Casual consent to treatment: a neglected issue in our health care system. Ann Pak Inst Med Sci 2006; 2: 207-12.

3. Leclercq WK, Keulers BJ, Houterman S, Veerman M, Legemaate $\mathrm{J}$, Scheltinga MR. A survey of the current practice of the informed consent process in general surgery in the Netherlands. Patient Saf Surg 2013; 7: 4. doi: 10.1186/1754-9493-7-4

4. Wheeler R. Consent in surgery. Ann R Coll Surg Engl 2006; 88: 261-4. doi: 10.1308/003588406X106315

5. Ochieng J, Ibingira C, Buwembo W, Munabi I, Kiryowa H, Kitara $D$, et al. Informed consent practices for surgical care at university teaching hospitals; a case in a low resource setting. BMC Med Ethics 2014; 15: 40. doi: 10.1186/1472-6939-15-40

6. Ashraf B, Tasnim N, Saaiq M, Zaman KU. Informed consent for surgery: Do our current practices conform to the accepted standards? J Coll Physicians and Surg Pak 2014; 24: 775-7.

7. Abed H, Rogers R, Helitzer D, Warner TD. Informed consent in gynecologic surgery. Am J Obstet Gynecol 2007; 197: 674-5. doi: 10.1016/j.ajog.2007.08.066

8. Jukic M, Kvolik S, Kardum G, Kozina S, Tomic JA. Knowledge and practices of obtaining informed consent for medical procedures among specialist physicians: questionnaire study in 6 Croatian hospitals. Croat Med J 2009; 50: 567-74. doi: 10.3325/cmj.2009.50.567

9. Peters C. Consenting to medical treatment: legal requirements vs medical practice. Are healthcare providers exposing themselves to potential legal action? N Z Med J 2009; 122: 50-9.

10. Fisher-Jeffes L, Barton C, Finlay F. Clinicians' knowledge of informed consent. J Med Ethics 2007; 33: 181-4. doi: 10.1136/ jme.2006.016758

11. Steinemann S, Furoy D, Yost F, Furumoto N, Lam G, Murayama K. Marriage of professional and technical tasks: a strategy to improve obtaining informed consent. Am J Surg 2006; 191: 696700. doi: 10.1016/j.amjsurg.2006.02.003

12. Leeper-Majors K, Veale JR, Westbrook TS, Reed K. The effect of standardized patient feedback in teaching surgical residents informed consent: results of a pilot study. Curr Surg 2003; 60: 615-22. doi: 10.1016/S0149-7944(03)00157-0

13. Pleat JM, Dunkin CS, Davies CE. Prospective survey of factors affecting risk discussion during consent in a surgical specialty. $\mathrm{Br}$ J Surg 2004; 91: 1377-80. doi: 10.1002/bjs.4590

14. Angelos $P$, Darosa DA, Bentram D. Residents seeking informed consent: are they adequately knowledgeable? Curr Surg 2002; 59: 115-8.

15. McGaughey I. Informed consent and knee arthroscopies: an evaluation of patient understanding and satisfaction. Knee 2004; 11: 237-42 doi: 10.1016/S0968-0160(03)00107-8

16. Jukic M, Kozina S, Kardum G, Hogg R, Kvolik S. Physicians overestimate patient's knowledge of the process of informed consent: a cross-sectional study. Med Glas 2011; 8: 39-45.

17. Chen AM, Leff DR, Simpson J, Chadwick SJ, McDonald PJ. Variations in consenting practice for laparoscopic cholecystectomy. Ann R Coll Surg Engl 2006; 88: 482-5. doi: 10.1308/003588406X114857

18. Schildmann J, Cushing A, Doyal L, Vollmann J. Informed consent in clinical practice: pre-registration house officers' knowledge, difficulties and the need for postgraduate training. Med Teach 2005; 27: 649-51. doi: 10.1080/01421590500138747

19. Gaeta T, Torres R, Kotamraju R, Seidman C, Yarmush J. The need for emergency medicine resident training in informed consent for procedures. Acad Emerg Med 2007; 14: 785-9. doi: 10.1111/j.1553-2712.2007.tb02352.x

20. Hutul OA, Carpenter RO, Tarpley JL, Lomis KD. Missed opportunities: a descriptive assessment of teaching and attitudes regarding communication skills in a surgical residency. Curr Surg 2006; 63: 401-9. doi: 10.1016/j.cursur.2006.06.016

21. Bollschweiler E, Apitzsch J, Obliers R, Koerfer A, Monig SP, Metzger $\mathrm{R}$, et al. Improving informed consent of surgical patients using a multimedia-based program? Results of a prospective randomized multicenter study of patients before cholecystectomy. Ann Surg 2008; 248: 205-11. doi: 10.1097/ 
SLA.0b013e318180a3a7

22. Eggers C, Obliers R, Koerfer A, Thomas W, Koehle K, Hoelscher $\mathrm{AH}$, et al. A multimedia tool for the informed consent of patients prior to gastric banding. Obesity (Silver Spring) 2007; 15: 286673. doi: $10.1038 /$ oby. 2007.340

23. Keulers BJ, Scheltinga MR, Houterman S, van der Wilt GJ, Spauwen PH. Surgeons underestimate their patients' desire for preoperative information. World J Surg 2008; 32: 964-70. doi: 10.1007/s00268-008-9581-1

24. de Vries EN, Eikens-Jansen MP, Hamersma AM, Smorenburg SM, Gouma DJ, Boermeester MA. Prevention of surgical malpractice claims by use of a surgical safety checklist. Ann Surg 2011; 253: 624-8. doi: 10.1097/SLA.0b013e3182068880

25. Betti S, Sironi A, Saino G, Ricci C, Bonavina L. Effect of the informed consent process on anxiety and comprehension of patients undergoing esophageal and gastrointestinal surgery. $J$ Gastrointest Surg 2011; 15: 922-7. doi: 10.1007/s11605-0111517-7

26. Temple WJ, Russell ML, Parson LL, Huber SM, Jones CA, Bankes $\mathrm{J}$, et al. Conservation surgery for breast cancer as the preferred choice: a prospective analysis. J Clin Oncol 2006; 24: 3367-73. doi: 10.1200/JCO.2005.02.7771

27. Breemhaar B, Van den Borne HW. Effects of education and support for surgical patients: the role of perceived control. Patient Educ Couns 1991; 18: 199-210.

28. Hoermann S, Doering S, Richter R, Walter MH, Schussler G. Patients' need for information before surgery. Psychother Psychosom Med Psychol 2001; 51: 56-61. doi: 10.1055/s2001-10754

29. Ashraf B, Saaiq M, Zaman KU. Qualitative study of Nocebo Phenomenon (NP) involved in doctor-patient communication. Int J Health Policy Manag 2014; 3: 23-27. doi: 10.15171/ ijhpm.2014.54

30. Cohen S. The nocebo effect of informed consent. Bioethics 2014; 28: 147-54. doi: 10.1111/j.1467-8519.2012.01983.x
31. Wells RE, Kaptchuk TJ. To tell the truth, the whole truth, may do patients harm: the problem of the nocebo effect for informed consent. Am J Bioeth 2012; 12: 22-9. doi: 10.1080/15265161.2011.652798

32. Nejadsarvari N, Ebrahimi A. Different aspects of informed consent in aesthetic surgeries. World J Plast Surg 2014; 3: 81-6.

33. Thorevska N, Tilluckdharyy L, Ticko S, Havasi A, AmoatengAdjepong $\mathrm{Y}$, Manthous CA. Informed consent for invasive medical procedures from the patient's perspective. Conn Med 2004; 68: 101-5.

34. Fink AS, Prochazka AV, Henderson WG, Bartenfeld D, Nyirenda C, Webb A, et al. Enhancement of surgical informed consent by addition of repeat back: a multicenter, randomized controlled clinical trial. Ann Surg 2010; 252: 27-36. doi: 10.1097/ SLA.0b013e3181e3ec61

35. Schenker Y, Fernandez A, Sudore R, Schillinger D. Interventions to improve patient comprehension in informed consent for medical and surgical procedures: a systematic review. Med Decis Making 2011; 31: 151-73. doi: 10.1177/0272989X10364247

36. Pesudovs K, Luscombe CK, Coster DJ. Recall from informed consent counselling for cataract surgery. J law Med 2006; 13 : 496-504.

37. Fink AS, Prochazka AV, Henderson WG, Bartenfeld D, Nyirenda $\mathrm{C}$, Webb A, et al. Predictors of comprehension during surgical informed consent. J Am Coll Surg 2010; 210: 919-26. doi: 10.1016/j.jamcollsurg.2010.02.049

38. Brezis $M$, Israel $S$, Weinstein-Birenshtock $A$, Pogoda $P$, Sharon A, Tauber R. Quality of informed consent for invasive procedures. Int J Qual health care 2008; 20: 352-7. doi: 10.1093/ intqhe/mzn025

39. Deyo RA, Cherkin DC, Weinstein J, Howe J, Ciol M, Mulley AG Jr. Involving patients in clinical decisions: impact of an interactive video program on use of back surgery. Med Care 2000; 38: 95969. doi: 10.1097/00005650-200009000-00009 